\title{
Primitive neuroectodermal tumour of the kidney: An unusual case mimicking renal angiomyolipoma with minimal fat
}

\author{
Jing Xie, MD; ${ }^{*}$ Jin Wen, MD; ${ }^{*}$ Ya-lan Bi, MD; Han-zhong Li, MD*
}

Jing Xie and Jin Wen contributed equally to this work.

*Department of Urology, Peking Union Medical College Hospital, Chinese Academy of Medical Sciences and Peking Union Medical College, Beiijng, China; 'Department of Pathology, Peking Union Medical College Hospital, Chinese Academy of Medical Sciences and Peking Union Medical College, Beiing, China

Cite as: Can Urol Assoc J 2015;9(5-6):E337-9. http://dx.doi.org/10.5489/cuai.2581

Published online May 13, 2015.

\section{Abstract}

Primitive neuroectodermal tumour (PNET) is a highly aggressive neoplasm that develops classically in the central nervous system. PNET of the kidney (rPNET) is extremely rare. Recently, a 23-yearold woman complained of left flank pain and intermittent hematuria for 3 months and was admitted to our hospital. A computed tomography $(\mathrm{CT})$ scan and magnetic resonance imaging demonstrated a $5.1 \times 4.4-\mathrm{cm}$ heterogenous mass with unconspicuous reinforcement in the upper pole of the left kidney. F18-FDG positron emission tomography CT (PET-CT) revealed the mass as a benign lesion with internal extensive bleeding. Renal angiomyolipoma with minimal fat was diagnosed. Three months later, a CT scan showed that the mass shrank to $3.1 \times 2.6 \mathrm{~cm}$ and nephron-sparing surgery of the left kidney was performed at the patient's request. However, histologic features and immunohistochemical analysis confirmed the diagnosis of rPNET. Five cycles of combined chemotherapy were executed. At the 11-month follow-up, the patient showed no evidence of metastasis or recurrence.

\section{Introduction}

Primitive neuroectodermal tumor (PNET) is a malignant round cell sarcoma of presumed neuroectodermal origin. It classically arises in the central nervous system and is rare in genitourinary system, such as the bladder, ${ }^{1}$ prostate, ${ }^{2}$ testis or uterus. ${ }^{3}$ In 1994, Mor reported the first case of PNET in the kidney (rPNET). ${ }^{4}$ Subsequently, rPNET has been sporadically reported. We present an unusual case of rPNET mimicking renal angiomyolipoma with minimal fat and managed with nephron-sparing surgery.

\section{Case report}

A 23-year-old woman was admitted to hospital with left flank pain, accompanied by fever and intermittent hematuria for 3 months. The clinical symptoms could not be relieved with anti-inflammatory agents. Abdominal ultrasound showed a hypoechoic mass in the upper pole of the left kidney. A contrast-enhanced computed tomography (CT) scan and magnetic resonance imaging (MRI) revealed a heterogenous mass of $5.1 \times 4.4 \mathrm{~cm}$ in size with multiple areas of hemorrhage and unconspicuous reinforcement (Fig. 1, parts A, B and C). Whole-body positron emission tomography CT (PET-CT) using 2- $\left[{ }^{18} \mathrm{~F}\right]$ fluoro-2-deoxy-D-glucose (FDG) showed no evidence of metastasis and the mass (standardized uptake value [SUV] 1.8) was considered a benign lesion with internal extensive bleeding. Therefore renal angiomyolipoma with minimal fat was diagnosed and the woman was advised to come back 3 months later. In February 2014, the CT scan revealed that the left kidney mass shrank to $3.1 \times 2.6 \mathrm{~cm}$, with mild heterogeneous enhancement (Fig. 1, part D).

During the patient's hospitalization, laboratory examinations were normal, with no evidence of tumour metastasis. Considering the patient's strong willingness to have the surgery, the potential malignancy (such as epithelioid angiomyolipoma), and the possibility of further hemorrhage, we performed nephron-sparing surgery of the left kidney and the mass resection was successful. Grossly, the tumour was mostly solid with interspersed areas of necrosis and hemorrhage. Histologically it was composed of monomorphic small round cells with scant cytoplasm and hyperchromatic round nucleus (Fig. 2, part A). In some areas, typical Homer Wright rosettes could be seen (Fig. 2, part B). Moreover, immunohistochemical analysis indicated the positive expression of CD99 (Fig. 2, part C) and vimentin (Fig. 2, part D) on tumour cell cytoplasmic membrane and $\mathrm{Ki}-67$ index was $15 \%$, which confirmed the diagnosis of rPNET. The patient 

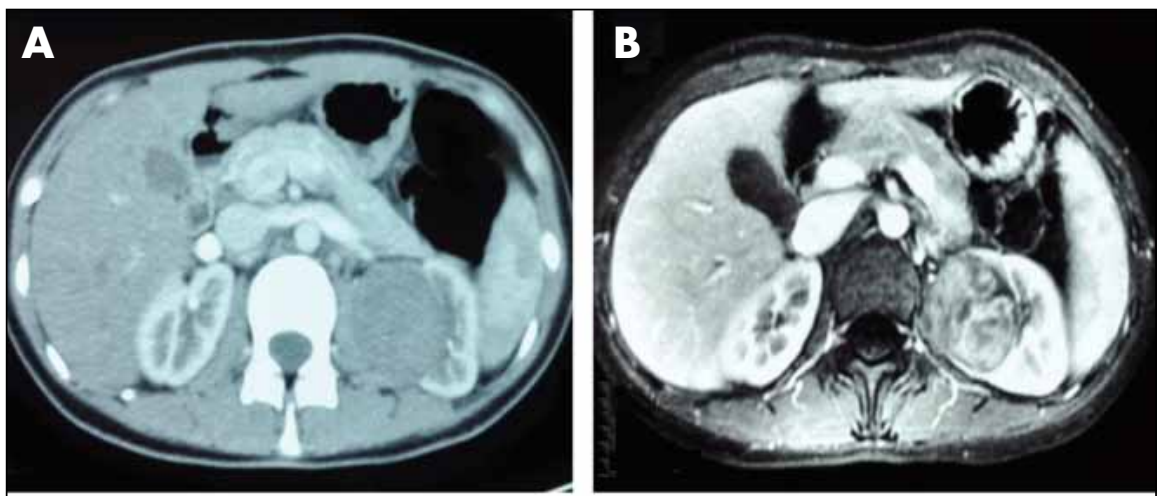

Fig. 1. The images of primitive neuroectodermal tumour. (A) A computed tomography (CT) scan showed a $5.1 \times 4.4-\mathrm{cm}$ mass with unconspicuous reinforcement in the left kidney. (B )Magnetic resonance imaging (MRI) revealed a heterogenous mass with multiple areas of hemorrhage. (C) Coronal MRI demonstrated a mass involving the upper pole of the left kidney. (D)Three months later, CT scan revealed the mass shrank to $3.1 \times 2.6 \mathrm{~cm}$.
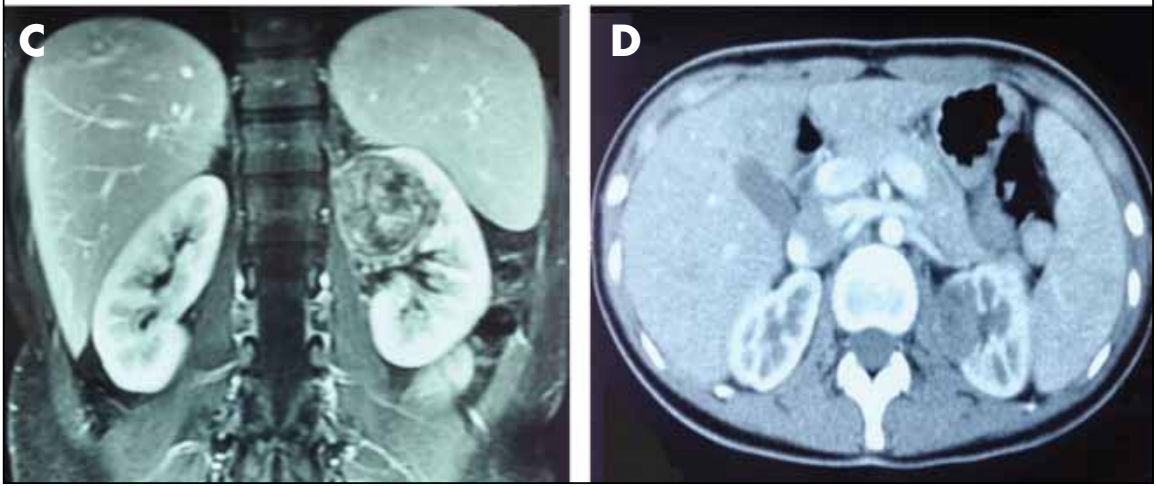

then was administered combined chemotherapy, including vincristine $\left(2 \mathrm{mg} / \mathrm{m}^{2}\right.$, day 1$)$, doxorubicin $\left(75 \mathrm{mg} / \mathrm{m}^{2}\right.$, day $1)$, cyclophosphamide plus mesna $\left(1200 \mathrm{mg} / \mathrm{m}^{2}\right.$, day 1$)$, dactinomycin $\left(1.25 \mathrm{mg} / \mathrm{m}^{2}\right.$, day 1$)$, ifosfamide plus mesna (1800 mg/m² daily, days $1-5)$ and etoposide $\left(100 \mathrm{mg} / \mathrm{m}^{2}\right.$ daily, days $1-5)$. The patient completed 5 cycles of chemotherapy and at the 11-month follow-up had no evidence of metastasis or recurrence.

\section{Discussion}

Reportedly, rPNET usually occurs in young adults, with an average age of 24 , and shows a slight male predominance. ${ }^{5}$ The clinical symptoms and images of rPNET are non-specific, making it difficult to distinguish it from other renal tumours. rPNET shows intense F18-FDG uptake, both in renal primary tumour and metastasis places. ${ }^{6}$ In our case, however, the mass showed low F-18 FDG uptake and shrank obviously in the course of disease, mimicking rupture and bleeding of renal angiomyolipoma with minimal fat. To our knowledge, this phenomenon has not been reported so far.

The diagnosis of rPNET is mainly based on histopathology and immunohistochemistry, supported by cytogenetic analysis. rPNET is characterized by small uniform round cells with focal Homer-Wright rosettes or perivascular seudo-rosettes formation. Membranous CD99 positivity is universal in rPNET and vimentin positivity has also been demonstrated. ${ }^{7}$ Standard cytogenetic analysis of rPNET show the translocation $\mathrm{t}(11 ; 22)(\mathrm{q} 24 ; \mathrm{q} 12)$ and is an supportive tool in making the final diagnosis. The histopathlogy and immunohistochemistry of our case confirmed classic rPNET.

rPNET is a highly aggressive tumour, with a tendency of local recurrence and early metastases to lungs, liver, bone and regional lymph nodes. The 5 -year disease-free survival rate is $45 \%$ to $55 \%$ and the median relapse-free survival is only 2 years in patients with metastatic disease. ${ }^{8}$ Multimodal therapeutic approaches, consisting of surgical resection, chemotherapy and radiotherapy, are needed to treat this malignancy. rPNET tends to be very large and the tumour diameter is usually $>10 \mathrm{~cm} .{ }^{9}$ Other reported cases indicated radical nephrectomy as treatment. ${ }^{9}$ In this case, we carried out nephron-sparing surgery for the first time because of the preoperative diagnosis and executed chemotherapy according to the pathological result. The patient has completed 5 cycles of chemotherapy, with no evidence of metastasis or recurrence. This case suggests that nephron-sparing surgery may be considered in early rPNET, but the long-term benefit is still unclear.

\section{Conclusion}

We reported an unusual case of rPNET confirmed by morphology and immunohistochemistry. rPNET is an extremely rare entity with aggressive biology behaviour and poor prognosis. It should always be considered in adolescents or young adults with a renal mass. The diagnosis of rPNET 

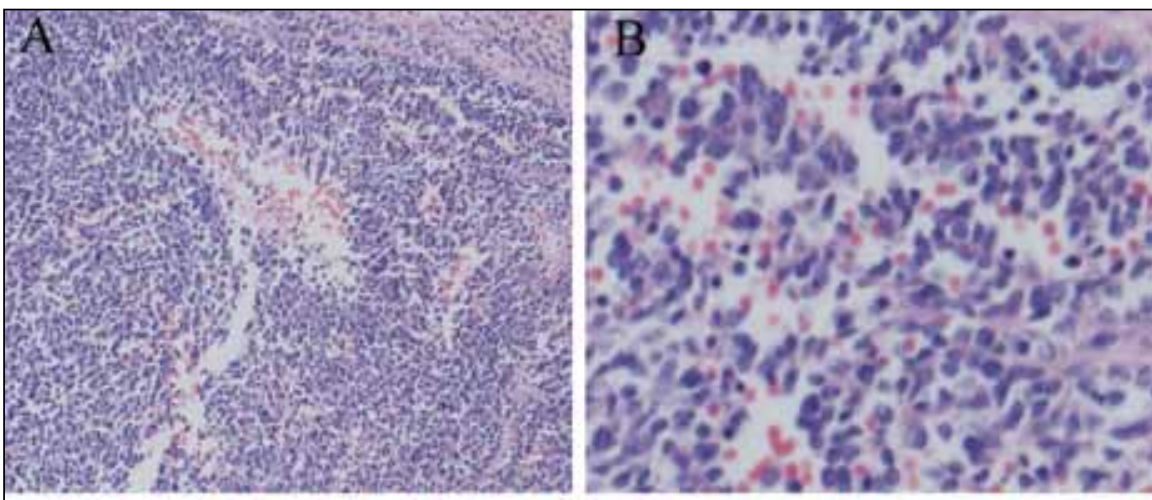

Fig. 2. Hematoxylin-eosin (H\&E) and immunohistochemical staining of the primitive neuroectodermal tumour. (A) The tumour was composed of small uniform round cells with scanty cytoplasm (H\&E, $\times 200)$. (B) In some areas, characteristic Homer-Wright rosettes could be seen $(\mathrm{H} \& \mathrm{E}, \times 200)$. (C) The tumour cells were diffusely positive for CD99 (immunohistochemistry, $\times 200$ ). (D) The tumour cells were positive for vimentin (immunohistochemistry, $\times 200$ ).
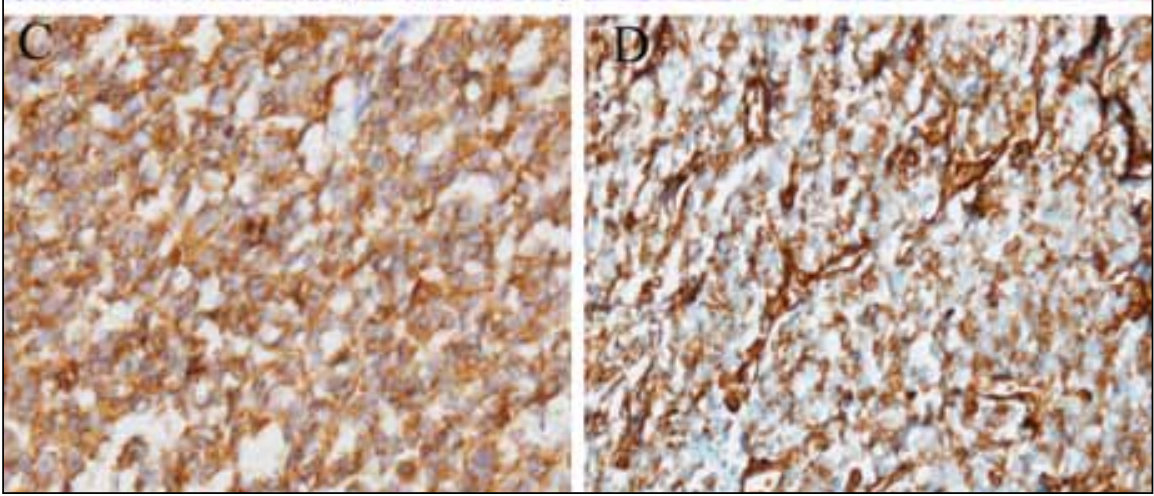

4. Mor Y, Nass D, Raviv G, et al. Malignant peripheral primitive neuroectodermal tumor(PNET) of the kidney. Med Pediatr Oncol 1994;23:437-40. http://dx.doi.org/10.1002/mpo.2950230508

is based on classical histologic features and immunohistochemistry, complemented by cytogenetics and molecular analysis. Our case suggests nephron-sparing surgery combined with chemotherapy may be considered in early rPENT, and we expect further evidence to support the long-term outcome.

Competing interests: The authors declare no competing financial or personal interests.

This paper has been peer-reviewed.

\section{References}

1. Zheng $Y$, Tan F, Wang $L$, et al. Primary primitive neuroectodermal tumor of the urinary bladder: A case report and literature review. Med Oncol 2011;28:S388-91. http://dx.doi.org/10.1007/s12032-0109680-3

2. Wu $T$, Jin $T$, Luo $D$, et al. Ewing's sarcoma/primitive neuroectodermal tumour of the prostate: A case report and literature review. Can Urol Assoc J 2013;7:E458-9. http://dx.doi.org/10.5489/cuaj.1393

3. Dizon AM, Kilgore LC, Grindstaff $A$, et al. High grade primitive neuroectodermal tumor of the uterus: $\mathrm{A}$ case report. Gynecol Oncol Case Rap 2013;7:10-2.

5. Ellinger J, Bastian PJ, Hauser $S$, et al. Primitive neuroectodermal tumor: Rare, highly aggressive differential diagnosis in urologic malignancies. Urology 2006;68:257-62. http://dx.doi.org/10.1016/i. urology.2006.02.037

6. Malhotra G, Swami A, Shah P, et al. F-18 fluorodeoxyglucose positron emission tomography "super scan" in a patient of metastatic primitive neuroectodermal tumor of the kidney. Indian J Nucl Med 2012;27:115-8. http://dx.doi.org/10.4103/0972-3919.110709

7. Marley EF, Liapis H, Humphrey PA, et al. Primitive neuroectodermal tumor of the kidney-another enigma: A pathologic, immunohistochemical, and molecular diagnostic study. Am I Surg Pathol 1997;21:354-9. http://dx.doi.org/10.1097/00000478-199703000-00013

8. Casella R, Moch H, Rochlitz C, et al. Metastatic primitive neuroectodermal tumor of the kidney in adults. Eur Urol 2001;39:613-7. htrtp://dx.doi.org/10.1159/000052514

9. Karpate A, Menon S, Basak R, et al. Ewing sarcoma/primitive neuroectodermal tumor of the kidney: Clinicopathologic analysis of 34 cases. Ann Diagn Pathol 2012;16:267-74. http://dx.doi. org/10.1016/i.anndiagpath.2011.07.011

Correspondence: Dr. Jing Xie, Department of Urology, Peking Union Medical College Hospital, Chinese Academy of Medical Sciences and Peking Union Medical College, Beijing, China; qyngnnyxi@126.com 